\title{
A Lesson in Black and White
}

\author{
Victor Wilson
}

I won't deny that a student of color on a predominantly white college campus faces a struggle. Above and beyond the worries, woes, and apprehensions that beset all college students, the student who represents an ethnic category often has to cope with an increased fear of isolation, and the role of always being different.

I can relate to students of color all too well. I'm an African-American male, and attended the University of Georgia for the first time in the fall of 1977 . The University of Georgia was then, and remains today, a predominantly white campus. I have progressed from student to Assistant to the President at UGA. I've had my share of struggles - from both my race and gender. I was terrified in September 1977 and, for the most part, remain a little scared today. Though I enjoy it immensely, my job reminds me every day that the exact opposite of black is white. Because society expects certain things of blacks and whites, this realization can be somewhat unnerving to a man of color.

But enrolling a student of color at a predominantly white campus can be a blessing to both the student and to the college community. Most important is presenting cultural diversity to all students. Students of all ethnic groups have credentials to teach the inherent benefits of plurality.

Because struggles as well as benefits will greet students of color on a predominantly white campus, they need a road map to their new academic environment. I offer the following:

\section{The Top Ten Tips for Students of Color at Predominately White Institutions}

Number 10: $\quad$ Accept the fact you will have challenges. They will be a part of your unique situation from day one, but as you've heard before, that which does not kill us makes us stronger. Meet these challenges headfirst.

Number 9: $\quad$ You should take pride in being a vessel of knowledge. No one knows you and your heritage better than you do. Share your knowledge with others. You are sharing one of the greatest subjects people can learn.

Number 8: $\quad$ Make sure you jump right in during those opportunities to educate others - there will be many teachable moments. Use them as often as you can. It will benefit you as well as those who need the lesson. 
Number 7: Don't let anyone of any race make you feel you shouldn't be proud of your college. Your reservoir of pride is as large as anyone else's.

Number 6: $\quad$ Encourage others to study and read about your heritage — you can't tell them everything. Don't turn away those who thirst for knowledge about you. Just point them in another direction.

Number 5: $\quad$ As questions and fears arise that you cannot answer, take time to read and find the answers to your questions. There is never anything wrong with learning about who you are. In fact, this acquisition of selfknowledge doesn't end with college, but often begins there.

Number 4: $\quad$ Try to interact with others who are like you. They're struggling too! This is the best way to disintegrate the feeling of increased loneliness many students report feeling.

Number 3: $\quad$ You must accept the fact that there may be preconceived notions about you before you set foot on campus. There may be some people who don't want you there. Don't worry, your rights are secure and the price for these rights has been paid already.

Number 2: $\quad$ Branch out! Not only should you help educate others about your culture, but also make sure to take time to learn about others and their customs. You will never have more opportunities to learn about your self and others than during your college years. It may be risky, but take the risk!

Number 1: In efforts to be accepted, under no circumstances sell your race short! It will be tempting to ignore who you are, but it will cause much pain in the long run. No matter how much you feel different, there will always be someone (probably more often than you think) who likes you just the way you are.

Every situation is different. The bottom line is simple; legally, everyone has the right to attend the college of his or her choice. Realistically, it's not always so easy for students of color. Yet, if utilized properly, the intrinsic lesson students of color offer, just by being there, can make a world of difference for themselves, the people they encounter, and the college as a whole. 